\title{
PENGARUH SUHU HYDROTHERMAL TERHADAP KARAKTERISTIK ZEOLIT YANG DISINTESIS DARI LIMBAH GEOTHERMAL
}

\author{
Deni Fajar Fitriyana ${ }^{1}$, Sulardjaka ${ }^{1}$, Norman Iskandar ${ }^{1}$, M. Dzulfikar ${ }^{2}$ \\ ${ }^{1}$ Departemen Teknik Mesin, Fakultas Teknik, Universitas Diponegoro \\ Jl. Prof. H. Soedarto, Tembalang, Kota Semarang 50275. \\ ${ }^{2}$ Jurusan Teknik Mesin, Fakultas Teknik, Universitas Wahid Hasyim \\ Jl. Menoreh Tengah X/22, Sampangan, Semarang 50236 \\ *Email: deniifa89@gmail.com
}

\begin{abstract}
Abstrak
Telah dilakukan sintesis zeolite berbahan dasar limbah geothermal dari Pembangkit Listrik Tenaga Panas Bumi (PLTP) Geo Dipa Energi, Dieng, Wonosobo, Jawa Tengah. Penelitian ini bertujuan untuk meneliti pengaruh suhu hidrotermal terhadap karakteristik zeolit yang disintesis dari limbah geothermal. Sebelum digunakan sebagai bahan dasar sintesis, lumpur geothermal terlebih dahulu dilakukan kalsinasi pada suhu $850^{\circ} \mathrm{C}$ selama 3 jam. Sintesis menggunakan metode hidrotermal dengan variasi suhu $100^{\circ} \mathrm{C}, 110^{\circ} \mathrm{C}$ dan $120^{\circ} \mathrm{C}$ selama 5 jam dengan $\mathrm{pH}>12$. Karakterisasi produk sintesis dilakukan dengan menggunakan spektroskopi serapan atom (AAS), difraktometer sinar$x(X R D)$ dan scanning electron microscope (SEM). Dari hasil uji AAS kandungan silika pada lumpur geothermal setelah proses kalsinasi meningkat dari 49,1\% menjadi 80.0426\%. Dari hasil analisis data XRD dan SEM, proses sintesis menghasikan zeolit A (variasi suhu $100^{\circ} \mathrm{C}, 110^{\circ} \mathrm{C}$ ) dan sodalit (variasi suhu $120^{\circ} \mathrm{C}$ ).
\end{abstract}

Kata Kunci: Sintesis, hidrotermal, zeolit A, Sodalit

\section{PENDAHULUAN}

Zeolit merupakan mineral yang istimewa karena struktur kristalnya mudah diatur, sehingga dapat dimodifikasikan sesuai dengan keperluan pemakai dan dapat digunakan untuk tujuan tertentu. Karena keistimewaannya itu zeolit dapat digunakan dalam berbagai kegiatan yang luas, seperti penukar ion, adsorben, dan katalisator. Akhir-akhir ini banyak peneliti yang melakukan penelitian daur ulang limbah menjadi bahan baku untuk zeolit sintesis. Misalnya abu sekam padi, abu layang batu bara, abu dasar batu bara dan limbah padat rumah tangga telah direkayasa untuk menghasilkan zeolit sintesis.

Putro dan Prasetyoko, (2007), telah melakukan penelitian mengenai penggunaan abu sekam padi sebagai sumber silika pada sintesis zeolit ZSM-5 tanpa menggunakan templat organik. Penelitian yang lain mengenai sintesis zeolit dengan bahan baku abu sekam padi dilakukan dengan menggunakan abu sekam padi untuk membuat zeolit beta. Ojha dkk (2004) telah melakukan sintesis zeolit berbahan abu layang batu bara untuk bahan sintesis zeolit $\mathrm{X}$ dengan metoge hydrothermal. Sintesis zeolit berbahan dasar abu layang batu bara juga dilakukan oleh Adamczyk dkk (2005) dengan menggunakan metode hydrothermal. Sedangkan untuk peneliti lokal juga melakukan penelitian tentang preparasi dan karakterisasi zeolit dari abu layang batubara secara alkali hydrothermal. Penelitian tersebut dilakukan Jumaeri dkk (2007). Bayati dkk (2008) telah melakukan penelitian tentang efek parameter sintesis terhadap kristalisasi dan ukuran inti zeolit pada zeolit $\mathrm{NaA}$ dengan metode hydrothermal.

Selain sintesis zeolit juga telah dilakukan banyak penelitian tentang modifikasi struktur zolit dengan melakukan penambahan surfraktan. Salah satunya dilakuakan oleh Warsito dkk (2008) yang melakukan penelitian terhadap Pengaruh penambahan surfraktan Cetyltrimethylammonium bromide (n-CTMABr) pada sintesis zeolit-Y (Milton, 1989). Penelitian inilah yang digunakan sebagai referensi dalam pembuatan natrium aluminat pada penelitian ini dengan berbagai modifikasi. Lain halnya dengan bahan - bahan diatas, pada penelitian ini bahan baku yang digunakan untuk sintesis zeolit adalah lumpur geothermal (geothermal sludge).

Asy'hari, dkk (2010), yang melakukan sintesis silika gel berbahan geothermal sludge dengan Metode Caustic Digestion. Dalam penelitian ini hanya menjelaskan pembuatan silika gel, atau bisa juga disebut pembuatan natrium silika karena hasil akhir dari penelitian ini mengahasilkan natrium silika. Penelitian inilah yang menjadi refrensi pembuatan natrium silika dalam penelitian ini dengan berbagai modifikasi. 
Zeolit sintesis adalah material yang meliki sifat fisik dan kimia yang hampir sama dengan sifak fisik dan kimia dari material zeolit alam. Zeolit merupakan kristal alumina-silika yang mempunyai struktur berongga atau berpori dan mempunyai sisi aktif yang bermuatan negatif yang mengikat secara lemah kation penyeimbang muatan. Komposisi zeolit dapat dengan baik dijelaskan dengan tiga komponen sebagai berikut:

$$
M_{\frac{n}{m}}^{m+} \cdot\left[S i_{1-n} A l_{n} O_{2}\right] \cdot n H_{2} O
$$

Dimana:

$$
\begin{array}{lll}
M_{\frac{n}{m}}^{+n+} & \begin{array}{l}
\text { merupakan extraframework kation } \\
\text { (unsur logam) }
\end{array} \\
{\left[\mathrm{Si}_{1-\mathrm{n}} \mathrm{Al}_{\mathrm{n}} \mathrm{O}_{2}\right]} & \text { merupakan kerangka zeolit } \\
\mathrm{nH}_{2} \mathrm{O} & \text { merupakan sorbed phase }
\end{array}
$$

Karena kandungan silika dalam lumpur geothermal cukup besar yaitu $80.0426 \%$, maka limbah ini berpotensi sebagai bahan dasar untuk mensintesis zeolit. Dalam penelitian ini akan dilakukan sintesis zeolit secara hidrotermal dengan bahan dasar lumpur geothermal yang didapat dari PLTP Dieng dengan variasi suhu hidrotermal yang dilakukan pada suhu $100^{\circ} \mathrm{C}$, $110^{\circ} \mathrm{C}$ dan $120^{\circ} \mathrm{C}$ selama 5 jam dengan $\mathrm{pH}>12$.

\section{METODE PENELITIAN}

Penelitian ini dilakukan secara dua tahap. Tahap pertama meliputi tahap preparasi dan identifikasi lumpur geothermal menggunakan metode Atomic Absorption Spectrophotometer (AAS) untuk mengetahui komposisi kimia lumpur geothermal dan X-Ray Diffractometer (XRD) untuk mengetahui fase yang terbentuk pada lumpur geothermal. Preparasi dilakukan dengan pengeringan lumpur geothermal yang dilanjutkan dengan proses kalsinasi pada suhu $850^{\circ} \mathrm{C}$ selama 3 jam. Pada tahap kedua dilakukan sintesis zeolit berbahan lumpur geothermal dengan metode hidrotermal. Untuk sintesis zeolit dimulai dengan membuat larutan natrium aluminat dengan cara melarutkan $4,5 \mathrm{gr} \mathrm{Al}(\mathrm{OH})_{3}$ sedikit demi sedikit kedalam $50 \mathrm{ml}$ larutan $\mathrm{NaOH}$ $5 \mathrm{M}$ dengan pengadukan pada suhu $100^{\circ} \mathrm{C}$. Sedangkan natrium silikat dibuat dengan cara 3 gram serbuk geothermal yang telah dilakukan preparasi ditambah dengan $30 \mathrm{~mL} \mathrm{NaOH} 5 \mathrm{M}$ kedalam $30 \mathrm{ml}$ larutan natrium aluminat, kemudian diaduk pada suhu kamar selama 2 jam dengan $200 \mathrm{rpm}$. sehingga diperoleh larutan natrium silikat yang homogen.

Untuk mengetahui pengaruh suhu hidrotermal terhadap pembentukan zeolit dilakukan variasi pemanasan pada suhu $100^{\circ} \mathrm{C}, 110^{\circ} \mathrm{C}$ dan $120^{\circ} \mathrm{C}$ selama 5 jam. Hasil yang terbentuk kemudian disaring dengan kertas saring whatmann untuk memisahkan antara padatan dan filtrate. Padatan yang terbentuk kemudian dicuci dengan larutan aquabidest. Padatan lalu dikeringkan dengan oven pada suhu $70^{\circ} \mathrm{C}$ selama 3 jam untuk mendapatkan hasil akhir yaitu serbuk zeolite.

\section{HASIL DAN PEMBAHASAN \\ Karakterisasi Serbuk Geothermal \\ Hasil pengujian AAS}

Tabel 1 menunjukan komposisi kimia serbuk geothermal dari hasil pengujian AAS. Sebelum preparasi, kandungan $\mathrm{SiO}_{2}$ serbuk geothermal sebesar $49,10 \%$. Sedangkan kandungan $\mathrm{Al}_{2} \mathrm{O}_{3}$ sangat kecil yaitu hanya $0.0559 \%$. Untuk mendapatkan serbuk geotermal dengan kandungan $\mathrm{SiO}_{2}$ yang lebih tinggi maka harus dilakukan kalsinasi pada suhu $850^{\circ} \mathrm{C}$ selama 3 jam. Proses kalsinasi ini bertujuan untuk menghilangkan komponen organik yang dapat menguap pada temperatur yang cukup tinggi. Setelah preparasi, kandungan $\mathrm{SiO}_{2}$ serbuk geothermal sebesar 80,0426\% dan kandungan $\mathrm{Al}_{2} \mathrm{O}_{3}$ sebesar $0.142067 \%$.

Tabel 1 Hasil pengujian AAS sebelum dikalsinasi

\begin{tabular}{|c|l|c|c|}
\hline NO & Parameter & Sebelum Preparasi(\%) & Setelah Preparasi (\%) \\
\hline 1 & $\mathrm{~A} 12 \mathrm{O} 3$ & 0.0559 & 0.142067 \\
\hline 2 & $\mathrm{Fe} 2 \mathrm{O} 3$ & 0.1919 & 0.4506 \\
\hline 3 & $\mathrm{Na} 2 \mathrm{O} 3$ & 0.6088 & 0.7601 \\
\hline 4 & $\mathrm{SiO} 2$ & 49.1 & 80.0426 \\
\hline
\end{tabular}

\section{Hasil pengujian XRD}

Gambar 1 menunjukan difraktogram serbuk geotermal sebelum kalsinasi (a) dan setelah preparasi (b). Pada serbuk geothermal sebelum preparasi menunjukan belum adanya peak dominan sehingga dapat disimpulkan serbuk geothermal hanya mengandung silika non kristal atau berbentuk amorf. Sedangkan setelah preparasi ditemukan peak pada $2 \theta 21.91$ dan 20.88 yang memiliki intensitas relatif sebesar 100 dan 40. Berdasarkan data pada software JCPDS, peak tersebut menunjukan terbentuknya silika mikrokristal yaitu cristobalite (JCPDS nomer 030267). 


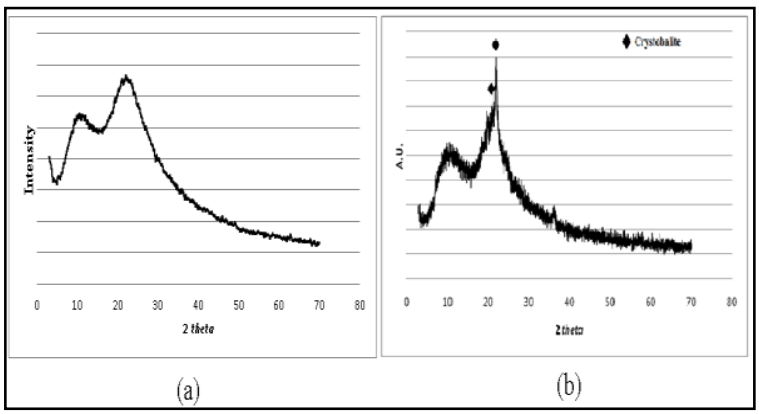

Gambar 1. Difraktogram serbuk geotermal sebelum preparasi (a) dan setelah preparasi (b)

\section{Karakterisasi Padatan Hasil Sintesis Hasil pengujian AAS}

Tabel 2 menunjukan hasil uji AAS pada produk hasil sisintesis. Berdasarkan hasil AAS, rasio $\mathrm{Si} / \mathrm{Al}$ dalam zeolit sintesis dengan metode hydrothermal sebesar 1,788. Hal ini sesuai dengan literatur bahwa zeolit A memiliki perbandingan rasio $\mathrm{Si} / \mathrm{Al} \quad 1-3,5$ dan sodalit dengan rasio $\mathrm{Si} / \mathrm{Al}$ kurang dari 2.

Tabel 2. Hasil analisis rasio $\mathrm{Si} / \mathrm{Al}$ dengan $\mathrm{AAS}$

\begin{tabular}{|c|c|c|}
\hline No & Parameter & Komposisi (\%) \\
\hline 1 & $\mathrm{~A} 1$ & 5.865333 \\
\hline 2 & $\mathrm{Si}$ & 10.48667 \\
\hline
\end{tabular}

\section{Hasil pengujian XRD}

Gambar 2 menunjukan hasil uji XRD pada zeolit setelah proses sintesis dengan variasi suhu hidrotermal $100^{\circ} \mathrm{C}, 110^{\circ} \mathrm{C}$ dan $120^{\circ} \mathrm{C}$ selama 5 jam. Berdasarkan hasil XRD menunjukan adanya kesesuian peak dari difraktogram zeolit hasil sintesis terhadap data JCPDS nomor 11-0401 (Sodalite) dan nomor 31-1269 (Zeolit A). Sehingga dapat disimpulkan pada ketiga variasi waktu hidrotermal terbentuk zeolit A dan sodalit. Dari hasil analisis XRD juga dapat menentukan ukuran butir suatu kristal dan derajat kristalinitasnya. Metode ini dilakukan dengan cara mencocokan data hasil percobaan dengan data yang terdapat pada JCPDS. Setelah kedua data dicocokan, maka harus diambil tiga peak yang paling dominan yang terdapat pada data JCPDS (metode scherrer).

Dengan persamaan scherrer, dapat digunakan untuk menentukan ukuran kristal yang terbentuk.

$$
\mathrm{L}=\frac{57.3 \times k \times \lambda}{\text { FWHM } \times \cos \theta}
$$

Keterangan:

$\begin{array}{lll}\mathrm{L} & = & \text { Ukuran bulir Kristal }(\mathrm{nm}) \\ \mathrm{k} & = & \text { Suatu konstanta oksida } \\ \lambda & = & (0,94) \\ \lambda & & \text { Panjang gelombang sinar X }\end{array}$

$\begin{array}{lll}\text { FWHM } & = & \begin{array}{l}\text { saat pengujian }(1,5406 \AA \text { Full } \\ \text { Fuldth half maximum } \\ \text { (lihat data pengujian) }\end{array} \\ \theta & = & \begin{array}{l}\text { Sudut posisi puncak } \\ \text { difraksi Kristal }\end{array} \\ 57,3 & =\begin{array}{l}\text { Faktor koreksi dari derajat } \\ \text { ke radian }\end{array}\end{array}$

Sedangkan untuk persen kristallinitas (\%w) dapat dihitung dengan menggunakan persamaan dibawah ini Kristallinitas $(\% \mathrm{w})=\frac{\frac{l}{I 0} \text { sample }}{\frac{l}{I 0} \text { standard JCPDS }} \times 100 \%$ I/Io $\quad=\quad$ Intensitas pada grafik XRD

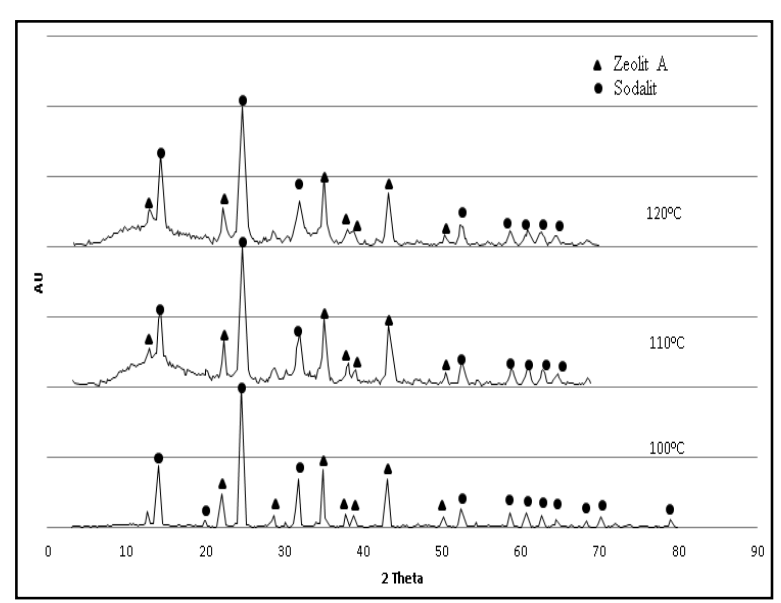

Gambar 2. Difraktogram tiga variasi zeolit hasil sintesis

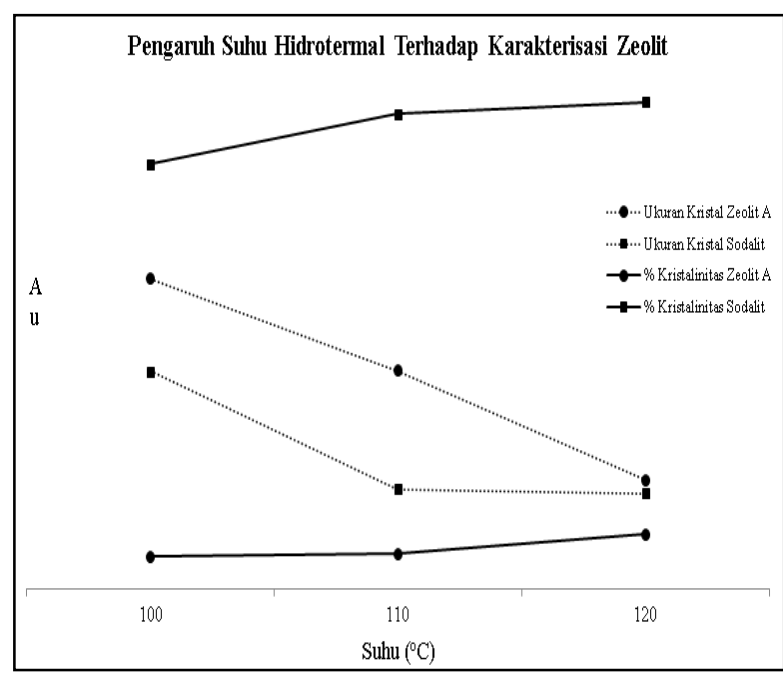

Gambar 3. Pengaruh suhu hydrothermal terhadap ukuran kristal dan \% kristalinitas zeolit hasil sintesis

Semakin tinggi suhu hydrothermal akan mengakibatkan ukuran kristal yang terbentuk akan semakin kecil pada zeolite A dan sodalit 
seperti yang ditunjukan Gambar 3. Peningkatan suhu hidrotermal berpengaruh dalam tahap pembentukann kristal, yaitu terjadi pada fase stabil dimana gel amorf akan mengalami penataan ulang pada strukturnya oleh adanya pemanasan sehingga dapat terbentuk embrio inti kristal. Semakin tinggi suhu hidrotermal maka pembentukann inti kristal semakin banyak sehingga pertumbuhan kristalnya semakin lama yang mengakibatkan ukuran kristalnya semakin kecil. Hal ini terjadi karena peningkatan suhu hidrotermal akan menyebabkan terjadinya peningkatan \%kritallinitas sampai batas tertentu sehingga tingkat nukleasi dan laju pertumbuhan akan semakin meningkat.

\section{Hasil pengujian SEM}

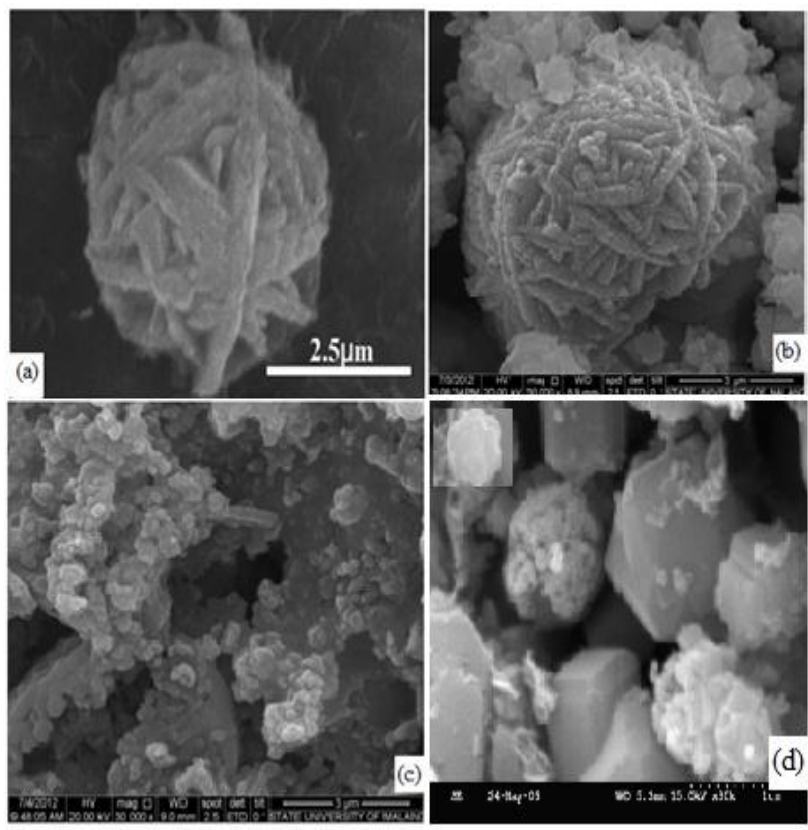

\section{Gambar 4. Hasil pengujian SEM terhadap zeolit sintesis.}

Dari hasil pengujian SEM pada zeolit yang disintesis dengan variasi $100^{\circ} \mathrm{C}$ dan $120^{\circ} \mathrm{C}$ selama 5 jam didapatkan hasil seperti Gambar 4 (b) dan (c). Gambar 4 (a) dan (d) masing masing merupakan gambar hasil penujian SEM pada sodalit yang dilakukan oleh Wajima et al. / Journal of Hazardous Materials B132 (2005) 244-252 dan SEM zeolite A yang di hasilkan Maysson Salam pada penelitian sistesis zeolit dengan bahan dasar municipal solid waste dengan metode hydrothermal menghasilkan beberapa jenis zeolit, seperti zeolit A dan sodalit. Gambar 4 (b) dan (c) menunjukan bentuk kubus dengan ukuran lebih kecil dan halus merupakan bentuk dari kristal sodalite. Sedangkan kubus dengan ukuran yang lebih besar merupakan kristal dari zeolit A. Dari Gambar 4 (b) dan (c), dapat dilihat bahwa kubus dengan ukuran kecil lebih dominan jika dibandingkan dengan kubus yang berukuran lebih besar. Hal ini sesuai dengan \%kristalinitas pada Gambar 3 dimana didapatkan hasil bahwa sodalit lebih banyak jika dibandingkan dengan zeolit A.

\section{KESIMPULAN}

Berdasarkan penelitian yang telah dilakukan, maka dapat di ambil kesimpulan:

1. Serbuk geothermal memiliki kandungan silika sebesar 80,0426\% sehingga dapat digunakan sebagai sumber silika dalam sintesis zeolit.

2. Zeolit yang disintesis dari serbuk geothermal menghasilkan zeolit jenis zeolit A dan Sodalit. Peningktan suhu hydrothermal berpengaruh terhadap struktur kristal yang terbentuk. Dengan peningkatan suhu hydrothermal, \%kristallinitas akan meningkat dan penurunan ukuran kristal zeolit sintesis dengan bahan dasar serbuk geothermal.

\section{DAFTAR PUSTAKA}

Adamczyk, Z \& Biaecka, B. 2005. Hydrothermal Synthesis of Zeolites from Polish Coal Fly Ash. Instutute of Applied Geology \& Central Mining Institute. Poland.

Asy'hari, Khoirul Anwar \& Amirulloh, Afifudin. 2010. Sintesa Silika Gel dari Geothermal Sludge dengan Metode Caustic Digestion. Laboratorium Elektrokimia dan Korosi Jurusan Teknik Kimia FTI-ITS. Surabaya.

Bayati, B. Babaluo, A.A \& Karimi, R. 2008. Hydrothermal synthesis of nanostructure $\mathrm{NaA}$ zeolite: The effect of synthesis parameters on zeolite seed size and crystallinity. Sahand University of Technology Tabriz. Islamic Republic of Iran.

Downsd, Robert T. Rakovan, John F. 2005. Zeolite synthesis from paper sludge ash at low temperature $\left(90^{\circ} \mathrm{C}\right)$ with addition of diatomite. Kyoto University, Sakyo-ku, Kyoto .Japan.

Jumaeri, W. Astuti dan W.T.P. Lestari. 2007. Preparasi dan Karakterisasi Zeolit dari Abu Layang Batubara Secara Alkali Hydrothermal. Jurusan Kimia Fakultas MIPA UNNES. Semarang.

Milton, Robert M. Molecular Sieve Science and Technology. Occelli, Mario L. \& Robson, Harry E (editor). 1989. Zeolite Synthesis. Louisiana State University. Washington DC.

Ojha, Keka. Pradhan, Narayan C \& Samanta, Amar Nath.2004. Zeolite from fly ash: 
synthesis and characterization. Department of Chemical Engineering, Indian Institute of Technology, Kharagpur. India.

Putro, Andhi Laksono \& Prasetyoko, Didik. 2007. Abu Sekam Padi Sebagai Sumber Silika Pada Sintesis Zeolit ZSM-5 Tanpa Menggunakan Templat Organik. Laboratorium Kimia Anorganik Jurusan Kimia, Institut Teknologi Sepuluh Nopember, Kampus ITS Keputih. Surabaya.
Wajima, Takaaki. Hagaa, Mioko. Kuzawa, Keiko. Ishimoto, Hiroji. Tamadaa, Osamu. Ito, Kazuhiko. Nishiyama, Takashi.

Warsito, Sri. Sriatun \& Taslimah. (2008) The Influence Of Cetyltrimethylammonium bromide (n-CTMABr) Surfactant Addition On Zeolite -Y Synthesis. Kimia Anorganik, Jurusan kimia, Fak. MIPA, Universitas Diponegoro. Semarang. 